\title{
New Joining Technology for Optimized Metal/Composite Assemblies
}

\author{
Holger Seidlitz, Lars Ulke-Winter, and Lothar Kroll \\ Institute of Lightweight Structures, Chemnitz University of Technology, 09107 Chemnitz, Germany \\ Correspondence should be addressed to Holger Seidlitz; holger.seidlitz@mb.tu-chemnitz.de
}

Received 20 February 2014; Accepted 23 May 2014; Published 3 September 2014

Academic Editor: Jie Han

Copyright (C) 2014 Holger Seidlitz et al. This is an open access article distributed under the Creative Commons Attribution License, which permits unrestricted use, distribution, and reproduction in any medium, provided the original work is properly cited.

\begin{abstract}
The development of a new joining technology, which is used to manufacture high strength hybrid constructions with thermoplastic composites (FRP) and metals, is introduced. Similar to natural regulation effects at trees, fibers around the FRP joint become aligned along the lines of force and will not be destroyed by the joining process. This is achieved by the local utilization of the specific plastic flow properties of the FRT and metal component. Compared with usual joining methods-such as flow drill screws, blind and selfpiercing rivets-noticeably higher tensile properties can be realized through the novel process management. The load-bearing capability increasing effect could be proved on hybrid joints with hot-dip galvanized steel HX420LAD and orthotropic glass-as well as carbon-fiber reinforced plastics. The results, which were determined in tensile-shear and cross-shear tests according to DIN EN ISO 14273 and DIN EN ISO 14272, are compared with holding loads of established joining techniques with similar joining point diameter and material combinations.
\end{abstract}

\section{Introduction}

In the automotive industry, the trend towards the use of lightweight materials is particularly strong; it is being assumed that the proportion of fiber-reinforced thermoplastics (FRP) will continue to rise in the medium term. The backgrounds to this are not the least requirements for reduction in $\mathrm{CO}_{2}$ emissions for fleet consumption. For this, FRP offerdue to the high specific properties and good recyclabilityspecial advantages $[1-3]$. Similar to construction principles in nature, the fiber architecture of the textile can be optimally adapted to the complex and often superimposed loads. Due to the low synthesis temperature, several functional elements are also integrable in FRP structures.

For new vehicle concepts in multimaterial design (MMD), textile reinforced thermoplastics like thermoformable organic sheets can make a significant contribution to enhance the lightweight-properties and accordingly also to resource conservation. Organic sheets have a higher specific energy absorption capacity than comparable sheet metal-based constructions and are thus predestined for crash-absorbing applications in car bodies [4-6].
Manufacturing FRP/metal-hybrids can be realized by nonpositive (friction-based) as well as positive or firmly bonded joining approaches. They generally require several extra joining elements, which increase the weight of the assembly. In addition, the components to be joined must undergo extensive preliminary operations. This may include drilling of holes for bolted or riveted joints or activation of the joining surface by etching, grinding, and degreasing for adhesive bonding $[7,8]$. Drilling in particular as well as punching holes in connecting elements by means of a sharp tool results in undesirable fiber breakage in the composite at the joining point of the FRP. This interrupts the flow of force (force flux) in the reinforcing fibers, which means that the great potential of the fiber-reinforced composite can be exploited only to a limited extent $[9,10]$.

Therefore, the structural multimaterial design (MMD) with fiber-reinforced thermoplastics consequently requires load-capable joining systems that do not interrupt the flux of forces in load bearing fibers around the joining point.

New technology concepts derived from thermoforming processes like flow drilling at metal sheets and thermoforming of load adjusted holes at thermoplastic composites 


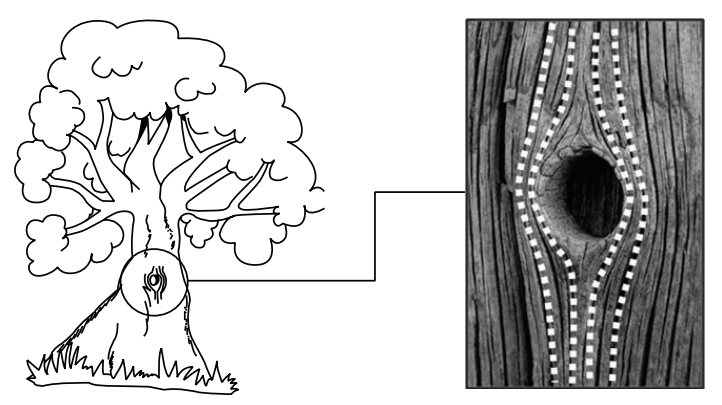

FIGURE 1: Reducing the stress concentration on knotholes of trees by load adjusted fiber orientation at the defect zone.

can be used as a solution approach. For the first time the fusion and adaptation of both technologies allow tolerant and reproducible joining of both material systems within a short process time, according to design principles in nature.

\section{Optimization of FRP-Joints following Examples in Nature}

Analyzing the structural regulation principles in nature and adapting to defect zones provides a blueprint for the shape optimization of a joining point. For instance, maintenance of a uniform stress distribution in the disturbed zone is observed in trees $[11,12]$. If a tree sustains damage by cracks, rottenness, or broken branches, a local structural weakness occurs. The resultant increased stress can be diminished by building up material in the vicinity of the defect $[13,14]$. Figure 1 shows how wood fibers are redirected radial at defects (e.g., caused by knotholes) as a way to counteract the "dangerous" notch effects.

This principle can be used (e.g., on drilled holes or cutouts) as a design model for the load-capable arrangement of reinforcing fibers on load application areas for technical FRP applications to increase strength. Based on this principle, optimization algorithms have been developed $[15,16]$ where fibers are aligned in the directions of principal stresses. Since the fiber component has the highest young's modulus in the longitudinal direction, the strength of the FRP component is gradual optimized by the specific arrangement of the reinforcing fibers in the direction of the principal stresses. The schematic procedure is described in Figure 2 with the aid of the finite element analysis (FEA) as an example of a tensileloaded unidirectional reinforced open-hole shell model.

\section{Load Adjusted Joining of Multimaterial Assemblies}

The principle of the flux of force oriented local fiber realignment-similar to designs in nature-has been implemented at the Institute of Lightweight Structures at Technische Universität Chemnitz into a new joining technology, which is suitable to manufacture multimaterial constructions with thermoplastic composites and metals. The developed joining method is particularly suitable for economic mass production.
Characterized by short cycle times and optimized joining spots with load path aligned fiber reinforcement, high loadbearing capabilities can be achieved as well as a high level of lightweight properties, so that it is applicable in various industrial sectors. Compared to typical joining methods, the main advantage is that no additional auxiliary joining element is required for the joining process.

3.1. Joining Sequence. When manufacturing a multimaterial joint, the flow properties of the metal and polymer component are exploited purposefully. With the help of a rotating mandrel, the metallic bushing becomes thermomechanically shaped from the metallic component. At the same time the bushing becomes formed through the FRP component, during the shaping process. After the mandrel is driven back, the closing head becomes manufactured through reforming the bushing with a special forming tool (Figure 3). Consequently, the key advantage consists in the avoidance of joining elements, which usually induce additional mass.

The rotation of the mandrel causes friction on the metal component. This thermal energy is locally induced into the FRP. As a consequence, the thermoplastic polymer becomes plasticized. This allows moving/aligning the embedded endless fibers, when the bushing is formed through the FRP component, so that fiber fracture does not occur and the force flux is still maintained (see Figure 4).

3.2. Dimensioning the FRP Joining Area. In order to ensure the radial displacement of fibers within the polymer matrix, a defined area must be plasticized by a heating system at the load introduction of the FRP component. As a result of inducing local heat, the viscosity of the thermoplastic polymer matrix can be reduced purposefully when the specific melting temperature is reached, so that it is possible to realign fibers by the flow drill tool and the formed bushing. Due to the local heating, fibers remain in the adjacent colder matrix material firmly clamped and become stretched differently during the realignment process. As a consequence, it is necessary to consider the joining point diameter as well as the maximum fiber elongation at fracture, to avoid fiber (FF) and interfiber fractures (IFF) at the joining area when dimensioning the FRP joint (Figure 5).

In the following, the realignment and the resulting length variation of the fiber reinforcement are described at the plasticized joining area by a geometric model of a unidirectional FRP ply, which considers the most deflected and therewith most stretched fiber at the edge of the joining point (Figure 6).

Because the diameter of the joining point $d_{\mathrm{JP}}$ is given and the realigned fiber with the length $l_{R}$ fits tangential at the edge of the joining point, the realignment $\operatorname{arc} \alpha_{R}$ and the wrap angle $\beta$ are equal. Out of this, the following relations can be derived:

$$
\begin{aligned}
& l_{\beta}=\alpha_{R} \cdot \frac{d_{\mathrm{JP}}}{2}, \\
& l_{0}=\frac{d_{\mathrm{JP}}}{2 \cdot \sin \alpha_{R}},
\end{aligned}
$$




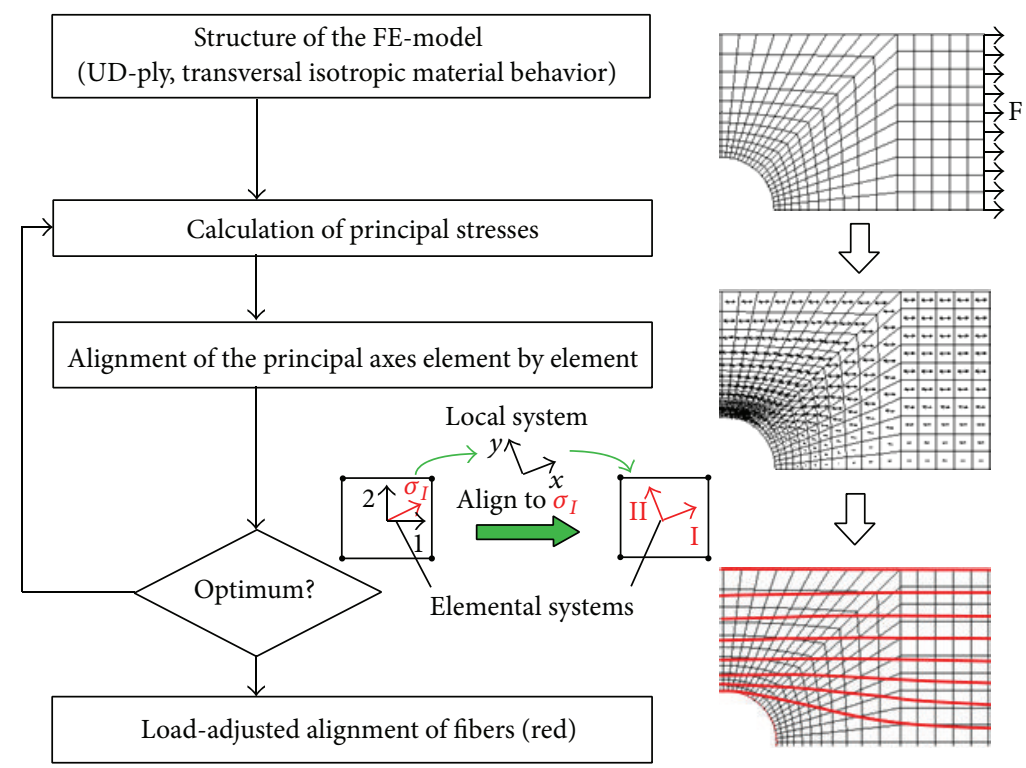

FIGURE 2: Determination of the optimum fiber orientation for a quarter model of a tensile-loaded UD-reinforced open-hole shell model.

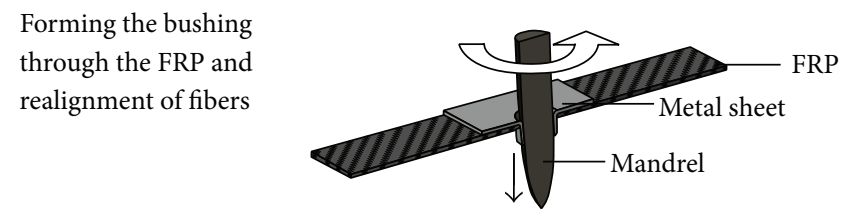

Manufacturing the closing head through reforming the bushing
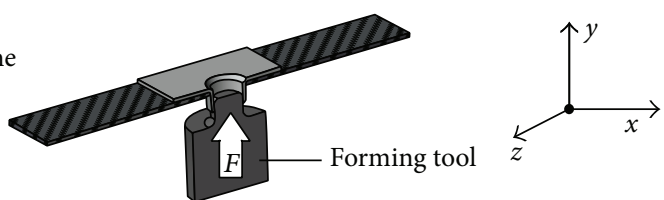

Nonpositive and positive joint
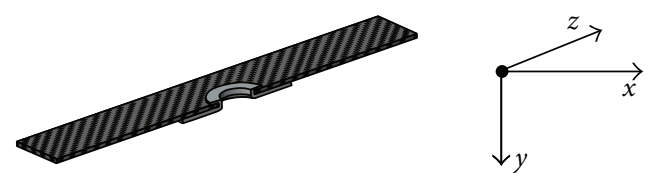

FIGURE 3: Principle of manufacturing a load adjusted metal/FRP joint.

$$
l_{R}=\frac{d_{\mathrm{JP}}}{2 \cdot \tan \alpha_{R}} .
$$

Furthermore, the maximum elongation of the fiber $\varepsilon_{B}$ is considered:

$$
\varepsilon_{B}=\frac{\Delta l}{l}=\frac{\left(l_{R}+l_{\beta}\right)-l_{0}}{l_{0}}=\frac{l_{R}+l_{\beta}}{l_{0}}-1 .
$$

Equation (1) in (2) gives

$$
\begin{aligned}
\varepsilon_{B} & =\frac{d_{\mathrm{JP}} / 2 \cdot \tan \alpha_{R}+\left(d_{\mathrm{JP}} / 2\right) \cdot \alpha_{R}}{d_{\mathrm{JP}} / 2 \cdot \sin \alpha_{R}}-1 \\
& =\cos \alpha_{R}+\alpha_{R} \cdot \sin \alpha_{R}-1 .
\end{aligned}
$$

In the following, the required diameters of the plasticized joining area, depending on the joining point diameter, are shown for FRPs with glass (GF) and carbon fiber reinforcement (Figure 7).

Through purposeful heating of the circular joining area, all realigned fibers have specific lengths as well as realignment arcs, which are depending from the distance to the joining point center. There are the following relations: 


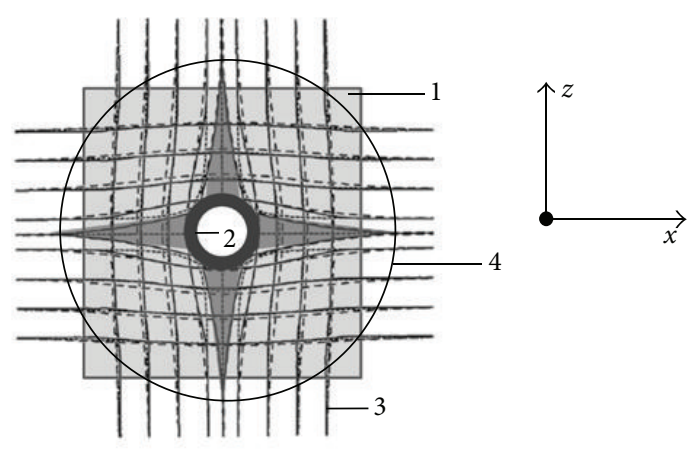

(1) Metal sheet

(2) Closing head

(3) Fibers of the FRP

(4) Area of fiber realignment

FIGURE 4: Schematic view of realigned fibers at the joint of an orthotropic FRP.

The boundaries of the plasticized joining area can be described by the circle equation:

$$
x^{2}+y^{2}=\left(\frac{d_{\mathrm{PA}}}{2}\right)^{2}
$$

so that every length $l_{0}$ of an unloaded fiber in the plasticized joining area can be determined. Therewith, it follows for $x=$ $l_{0}(y)$ :

$$
l_{0}(y)=\sqrt{\frac{1}{4} \cdot d_{\mathrm{PA}}^{2}-y^{2}}
$$

The realignment of fibers occurs at the joint in the interval between $0 \leq y \leq d_{\mathrm{JP}} / 2$. At the same time, the fibers, which lie flat at edge of the joining point at $y=0$, are highly stressed. From $y=d_{\mathrm{IP}} / 2$, which corresponds to the radius of the joining point (Figure 6), fibers are not stretched. For the realignment, $\operatorname{arc} \alpha_{R}$ follows therewith:

$$
\tan \alpha_{R}=\frac{d_{\mathrm{JP}} / 2-y}{l_{0}(y)}
$$

Insert (6) in (7) gives the realignment $\operatorname{arc} \alpha_{R}$ as a function of the $y$-coordinate, for every realigned fiber of the plasticized joining area:

$$
\alpha_{R}(y)=\arctan \left(\frac{d_{\mathrm{PA}}-y}{\sqrt{(1 / 4) \cdot d_{\mathrm{PA}}^{2}-y^{2}}}\right) .
$$

With (8), considering (3), the strain of every fiber can be determined in the plasticized joining area, as long as $\alpha_{R}$ is small:

$$
\begin{aligned}
\varepsilon_{B}(y)= & \cos \left(\arctan \left(\frac{d_{\mathrm{PA}}-y}{\sqrt{(1 / 4) \cdot d_{\mathrm{PA}}^{2}-y^{2}}}\right)\right) \\
& +\arctan \left(\frac{d_{\mathrm{PA}}-y}{\sqrt{(1 / 4) \cdot d_{\mathrm{PA}}^{2}-y^{2}}}\right) \\
& \cdot \sin \left(\arctan \left(\frac{d_{\mathrm{PA}}-y}{\sqrt{(1 / 4) \cdot d_{\mathrm{PA}}^{2}-y^{2}}}\right)\right)-1
\end{aligned}
$$

Figure 8 shows the resulting strain course from (9) at CFRP and GFRP joint with a joining point diameter of $d_{\mathrm{Jp}}=5.3 \mathrm{~mm}$.

This shows that the located filaments at the joining point are prestressed in the region of the maximum fiber strain. Further tensile stress would cause fiber fracture and therewith premature component failure. To exploit the high potential of FRP component optimally, it is necessary to choose a larger diameter of the plasticized joining area. Internal material friction, which is caused during the realignment by superimposed drifting fibers in the plasticized matrix, was not considered in the model.

The arrangement of filaments in thickness direction also requires an increased plasticized joining area at the FRP joint. In the following, this parameter was chosen for GFRP/metal joints with $20.0 \mathrm{~mm}$ and CFRP/metal joints with $30.0 \mathrm{~mm}$ for a joining point diameter of $5.3 \mathrm{~mm}$ (Figure 7 ).

3.3. Development and Implementation of a Joining Device. To implement the described joining sequence technologically, an automated joining device was designed and manufactured (Figure 9).

Before joining, the metal and the FRP component are fixed in the cavity (11) by the fixing unit (Figure 9(d)). After closing the cavity, the rotating flow drill tool (6) will be inserted by the electromechanical drilling unit (5) through the borehole of the fixing plate (9) (Figure 9(b)). The plasticizing process can be supported at higher wall thicknesses with a special hot air heating system (1). The specific plasticization diameter of the joining area can be set through the diameter of the nozzle output at the cavity. So there is one cavity plate for joining GFRP with $20.0 \mathrm{~mm}$ and another one for CFRP with a diameter of $30.0 \mathrm{~mm}$.

After the bushing is formed through the FRP component, the fixing plate is reset by the pneumatic cylinders ( 7 and 10) and the abutment plate (8) moved forward, so that the cavity is closed and the forming process can be started by the forming unit (Figure 9(c)). For that, the forming tool (2) will be pressed by the pneumatic cylinder (4) in the bushing, so that it is everted. With the help of force transducer, which is arranged between the pneumatic cylinder and the forming tool, the forming force can be set. Through the use of a Programmable Logic Controller (PLC), the repeatable 


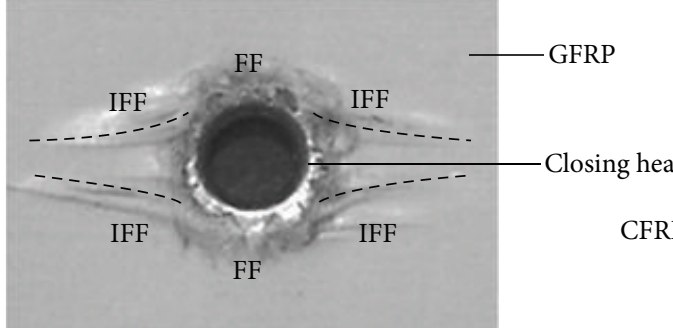

- - - Realigned fibers

(a)

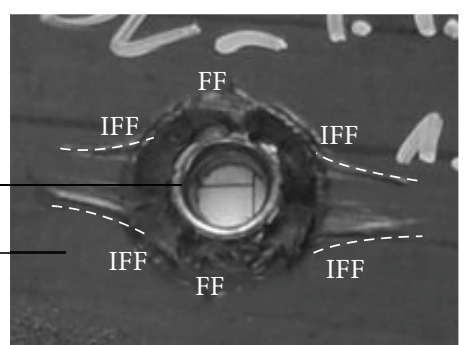

- - - Realigned fibers

(b)

FIGURE 5: FF and IFF, caused by too small plasticization area (a) at hybrid joints with glass (GFRP) and (b) carbon fiber reinforced plastics (CFRP).

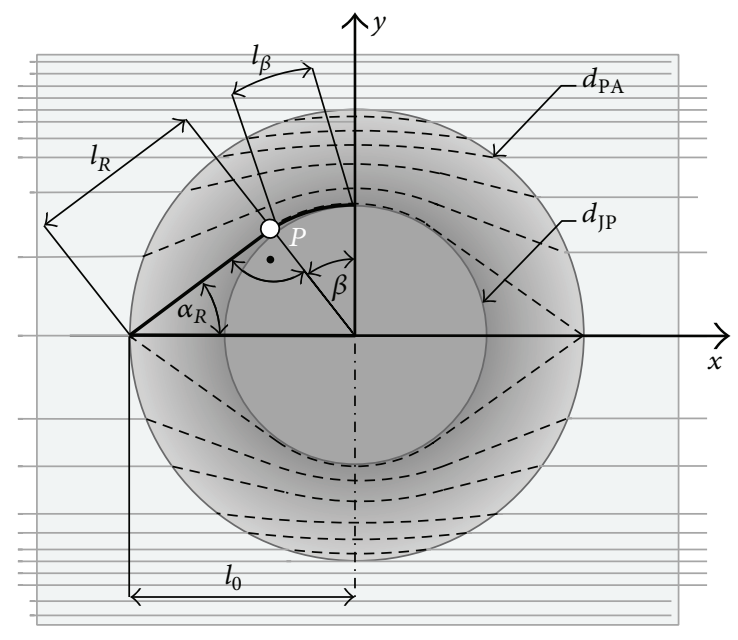

$d_{\mathrm{PA}}$ Diameter of the plasticized joining area

$d_{\mathrm{JP}} \quad$ Diameter of the joining point

$l_{0} \quad$ Length of the unloaded fiber

$P \quad$ Intersection of the tangent

$l_{R} \quad$ Length of the realigned fiber until $P$

$l_{\beta} \quad$ Arc length

$\alpha_{R} \quad$ Realignment arc

$\beta \quad$ Wrap angle at the edge of the joining point

FIGURE 6: Geometric model description of an unidirectional ply with the most deflected fiber and required diameter of the plasticized joining area.

control of the pneumatic drives and the hot air heating system as well as the drilling unit and the spindle are guaranteed. The PLC and other special assemblies such as the frequency and the safety devices are arranged in a cabinet below the machine table (12). On a control panel, it is possible to enter materialspecific joining parameters like spindle speed, the positions of the switching points, the required feed rates, and the heating time (Figure 10).

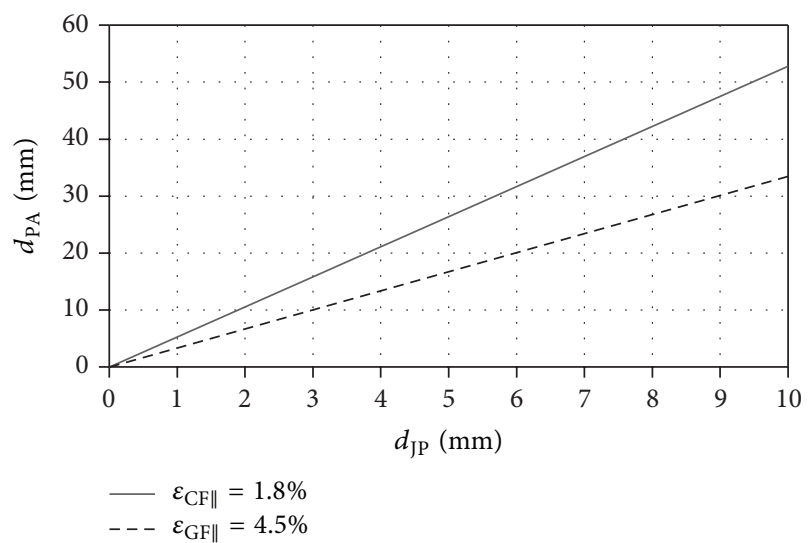

FIGURE 7: Required diameter of the plasticizing area at the FRP joint depending on the joining point diameter.

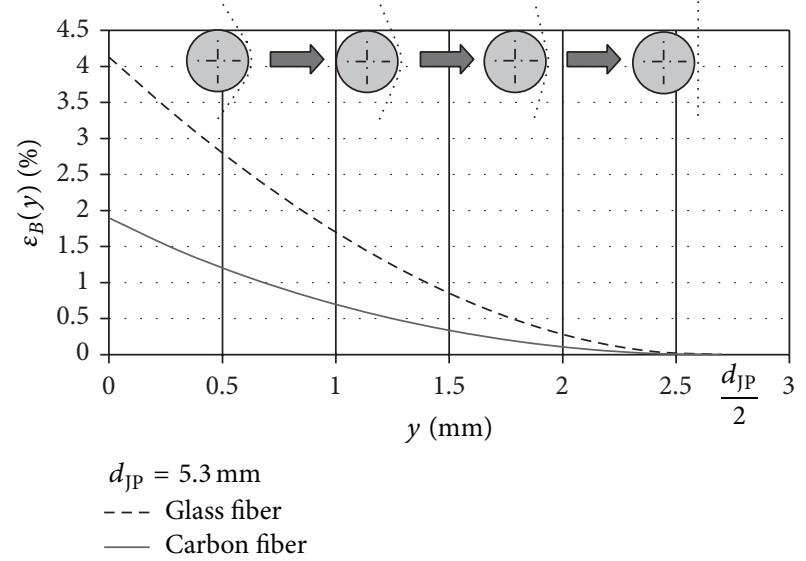

FIGURE 8: Strain of reinforcement fibers at the edge of the joining point in the plasticized joining area.

\section{Strength Behavior of High Strength FRP/Metal Joints}

4.1. Materials and Tests. To characterize the strength behavior of the multimaterial joining system, lap-shear and 
TABLE 1: Specification of tests and materials.

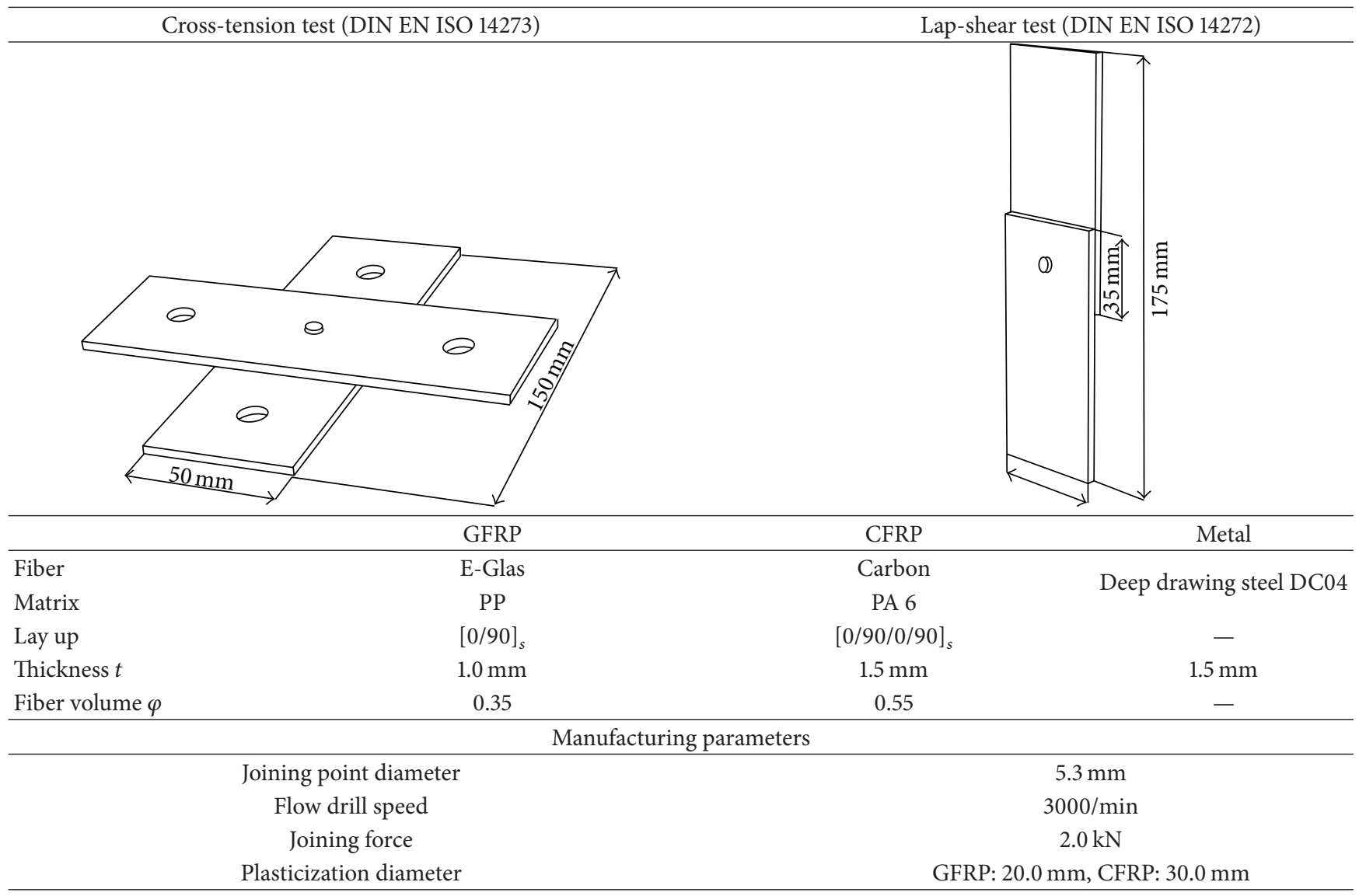

cross-tension tests according to DIN EN ISO 14273 and DIN EN ISO 14272 were realized. For that, hybrid joints with deep-drawing steel DC04 and orthotropic reinforced polypropylene (PP) as well as polyamide 6 (PA6) were manufactured. Table 1 summarizes the investigated joining material and production parameters.

4.2. Strength Influence of Realigned Fibers at GFRP and CFRP Joints. The load adjusted design of the load introduction at GFRP and CFRP components increases the lapshear strengths significantly. Compared with conventional predrilled FRP, the amount of load bearing fibers will not be reduced by the new joining process. Thereby, it is possible to reduce dangerous notch and bearing stress effects at the edge of FRP joints, so that considerably higher lap-shear strength can be transferred (Figure 11).

4.3. Influence of the FRP Wall Thickness. The innovative joining process, in addition to the previously illustrated joining studies with thin FRPs, is suitable for joints with relatively thick-walled composite structures. Referred to the wall thickness of the FRP component, the load-bearing capacity of the hybrid joining system increases until 1.4-fold of the metal thickness $(1.5 \mathrm{~mm})$, which is equal to a FRP wall thickness of $2.0 \mathrm{~mm}$ (Figure 12).
Furthermore a gradual abatement of the strength behavior is observed at tensile-shear loaded joints. In contrast, the determined cross-tension holding forces decrease strongly at a FRP wall thickness of $2.0 \mathrm{~mm}$, which is primarily caused by the reduced overlap length of the closing head flanks. As a result, the influence of the nonpositive character is notably declined, so that the joining strength decreases with intensifying FRP wall thickness and is mostly determined by the form lock of the joining point.

4.4. Comparison with Established Joining Methods. To rate the strength behavior of the new developed joining technology, lap-shear and cross-tension tests were carried out on established punctiform joints with equal material combinations as well as similar joining point diameters. In contrast to hybrid joints with FDS screws, blind and semihollow rivets, noticeable higher failure loads are achieved in lap-shear tests which can be explained by the integrative joining sequence and the load adjusted design of the FRP joint. Although the supporting surface of the closing head is less, similar holding forces as FDS joints can be obtained in cross-tension tests. However, the results of the strength tests confirm that, for both types of loads, noticeable increased loadbearing capacities can be realized as well as a reduced weight (Figure 13). 


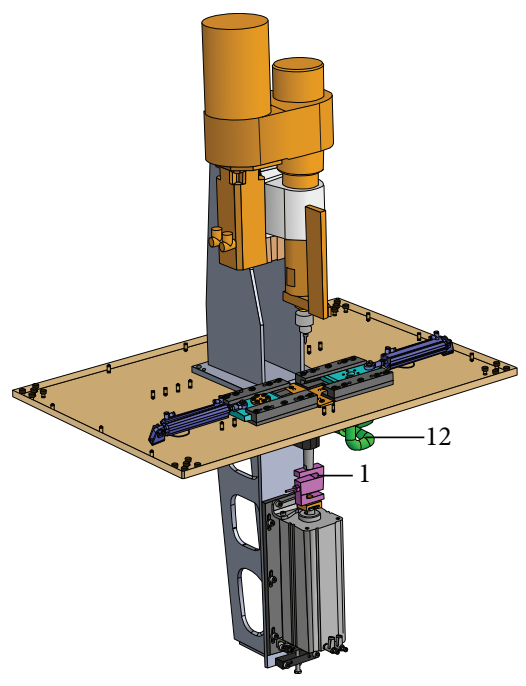

(a)

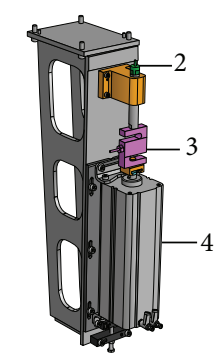

(c)

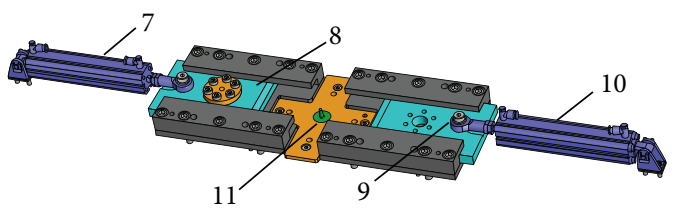

(d)

FIGURE 9: Joining device for the manufacturing of heavy duty hybrid joints: (a) basic components, (b) flow drill unit, (c) forming unit, and (d) fixing unit. (1) Hot air heating system with ring nozzle, (2) forming tool, (3) force transducer, (4) pneumatic cylinder for forming closing head, (5) drilling unit, (6) flow drill tool, (7) pneumatic cylinder/abutment, (8) abutment plate, (9) fixing plate, (10) pneumatic cylinder/fixing plate, (11) cavity with nozzle output, and (12) machine table.

\section{Discussion}

Towards conventional techniques the new load adjusted joining process occurs from the metal side and is supported by heat. This joining sequence in particular serves the FRP component, because fiber and interfiber fracture can be avoided at the joint. However, it can be seen that the realigned fibers are not only oriented in the direction of force-flux, but are also more concentrated in the joining spot than those in the rest of the material sections (Figure 14).

Caused by the radial displacement of fibers at the forming process of the bushing and through the formation of the closing head by the forming tool, noticeable higher fiber

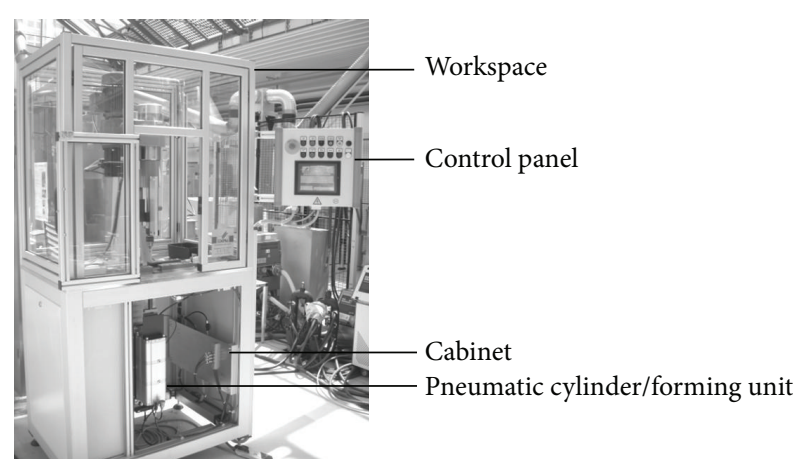

FIGURE 10: Joining device for manufacturing heavy duty hybrid joints.

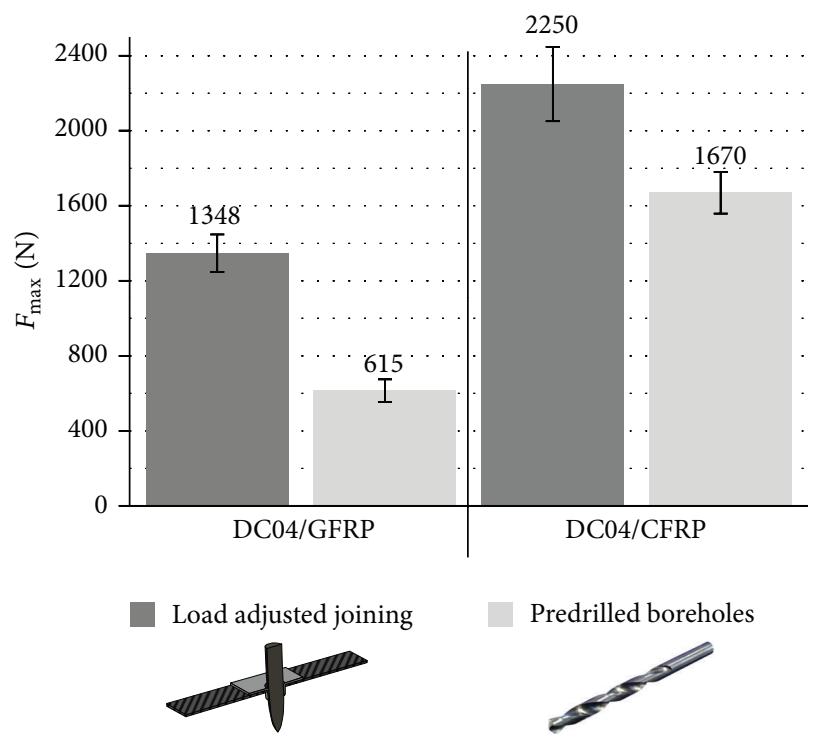

FIGURE 11: Lap-shear strengths of DC04/GFRP and DC04/CFRP joints with load adjusted formed and predrilled FRP bore holes.

concentration is achieved, which decreases at a distance of $a=2.5 \mathrm{~mm}$ to the normal level $(\varphi=0.35)$ of GFRP component (Figure 15).

The area of the fiber realignment is marked by the typical spandrel. The check measurement at the top plies of the FRP components confirms that the size of the plasticizing area for joining points-with a diameter of $5.3 \mathrm{~mm}$-was chosen correctly to guarantee the flexibility of the fibers (cf. Figures 7 and 16).

In particular, orientations of glass fibers in every single ply could be determined at the joint by incinerating the polymer matrix system (Figure 17). A nondestructive realignment of the reinforcing fibers is observed mainly at the closing head side unidirectional ply (Figure 17(a)). In spite of that, a little amount of fiber fracture is observed at inner plies (Figures $17(\mathrm{~b})$ and $17(\mathrm{c}))$. The intensity of FF increases up to the metal sheet (Figure 17(d)).

Furthermore, the orientations of the load path redirected fibers at the connection point can be proved by the use of computer tomography (CT) analyzing technology. Apart 


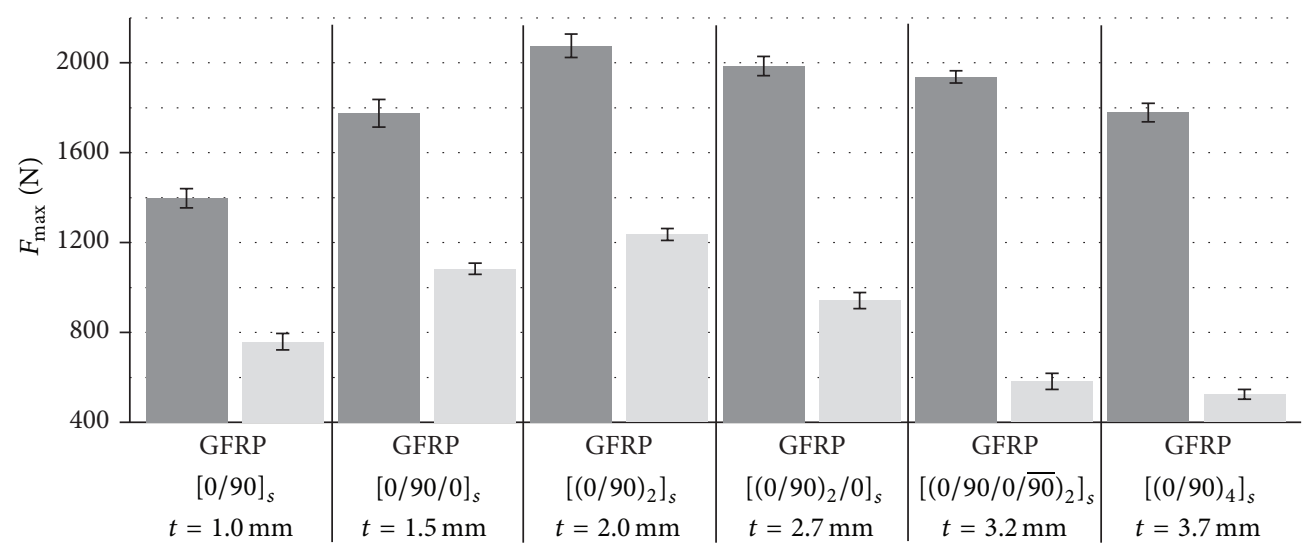

Lap-shear test

Cross-tension test

FIGURE 12: Failure loads of load adjusted hybrid joints in dependence of the FRP thickness, exemplarily illustrated by DC04/GFRP joints.

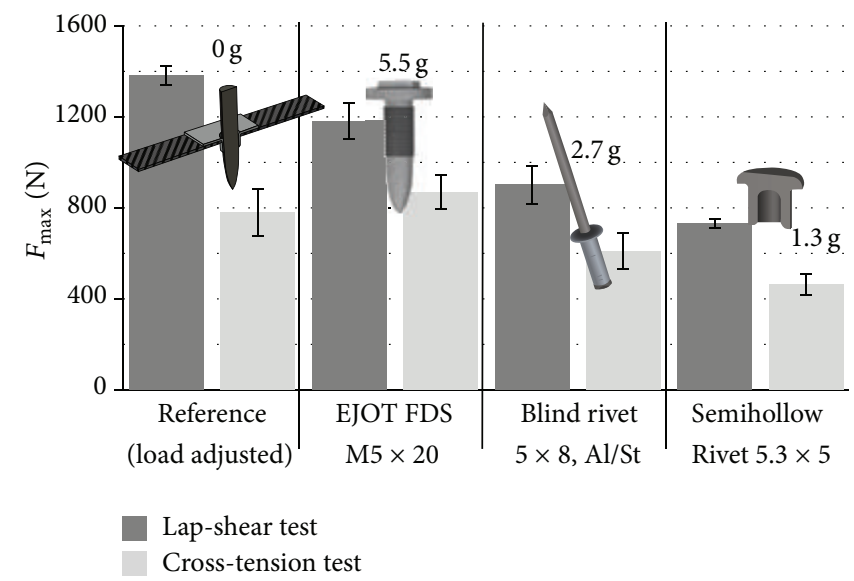

FIGURE 13: Failure loads of typical joining techniques compared with load adjusted hybrid DC04/GFRP joints.
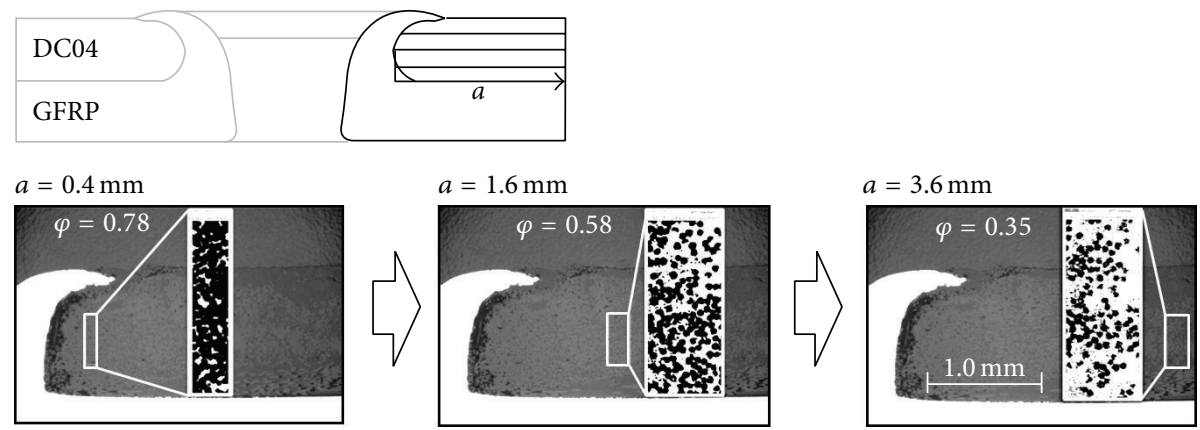

Figure 14: Micro section of a DC04/GFRP joint and analysis of the fiber volume.

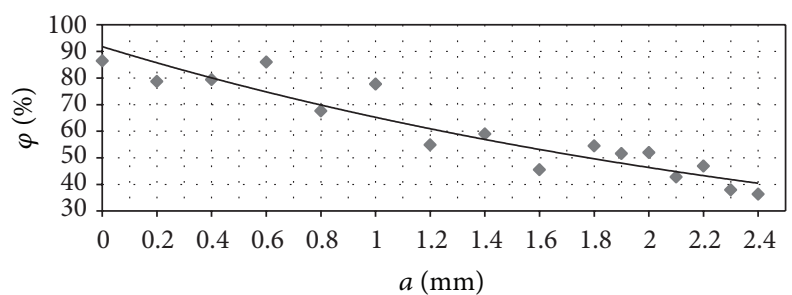

FIGURE 15: Fiber content in dependence of the distance to the edge of the joining point. 


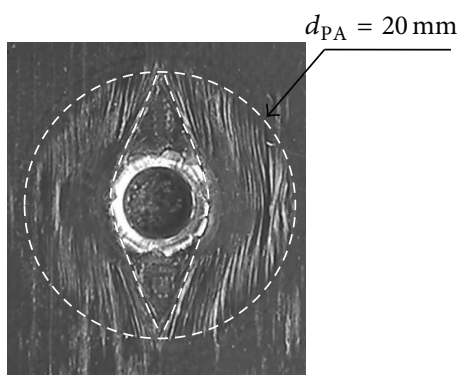

(a)

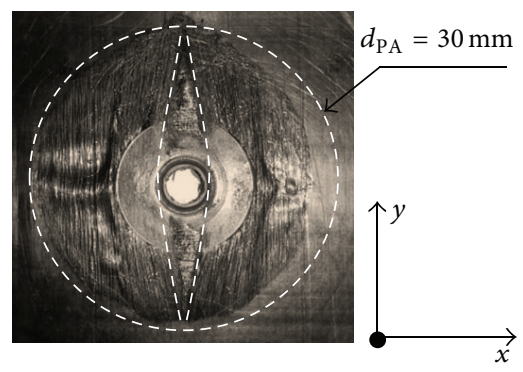

(b)

FIGURE 16: Realigned fibers at the top plies of (a) DC04/GFRP and (b) DC04/CFRP joints (right).

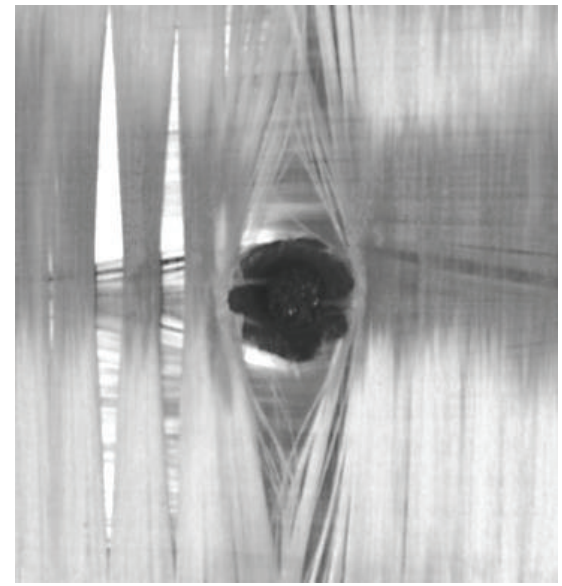

(a) $0^{\circ}$-ply

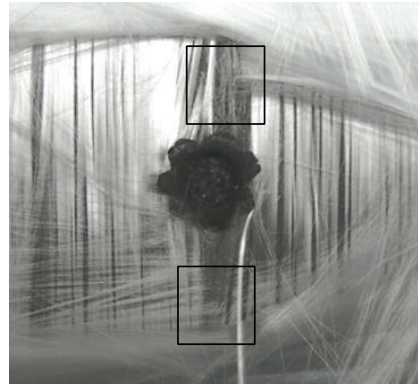

(c) $90^{\circ}$-ply

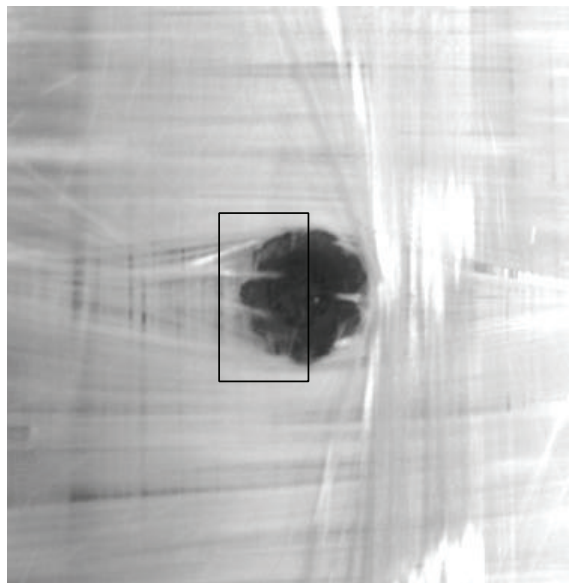

(b) $90^{\circ}$-ply

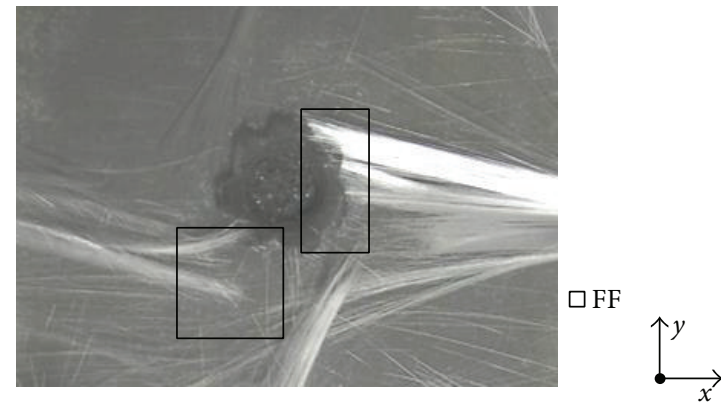

(d) $0^{\circ}$-ply

FIGURE 17: Analyzing the fiber orientation of DC04/GFRP joints by incineration.

from the tangential realigned course of the reinforcing fibers, it is visible that fiber fracture occurs at the joining point edges of the FRP component (Figure 18).

Fiber fractures (FF) are usually caused by the new joining process during formation of the bushing. Unlike the closing head-sided UD layers, which will be first pierced in the later course of the process by the rotating mandrel and, thus, will be expanded continuously, the UD layers at the metal sheet get in contact for the first time primarily with the formed bushing.

Once the mandrel pierces the metal sheet, a sharp-edged sleeve is formed. However, at this time, the mandrel is situated within the sleeve and, therefore, does not contribute to a steady realignment of all fibers in the load introduction area. With that, fibers are partially cut by the sharp edges of the formed bushing until the mandrel-with increasing load adjusted realignment fibers-completely penetrates the FRP component.

\section{Summary}

Typical mechanical joining techniques such as screwing, bolting, and riveting are causing fiber fractures at the FRP joint when manufacturing a FRP/metal hybrid. As a result of 


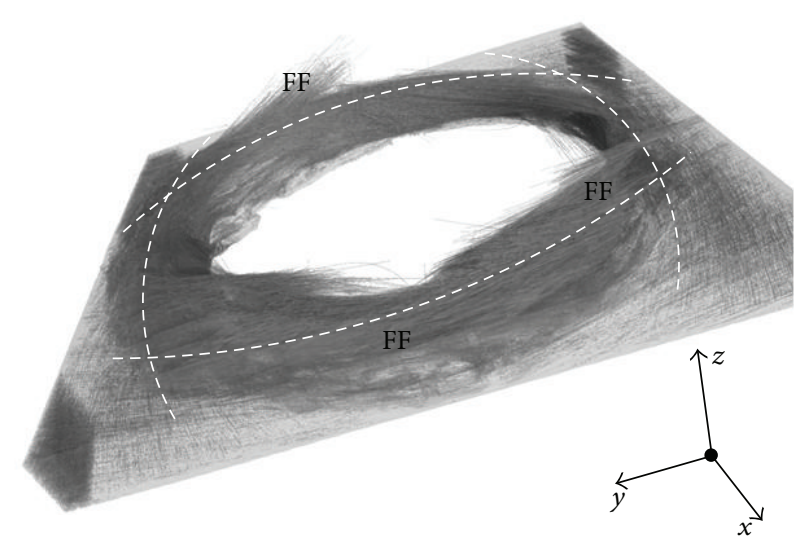

(a)

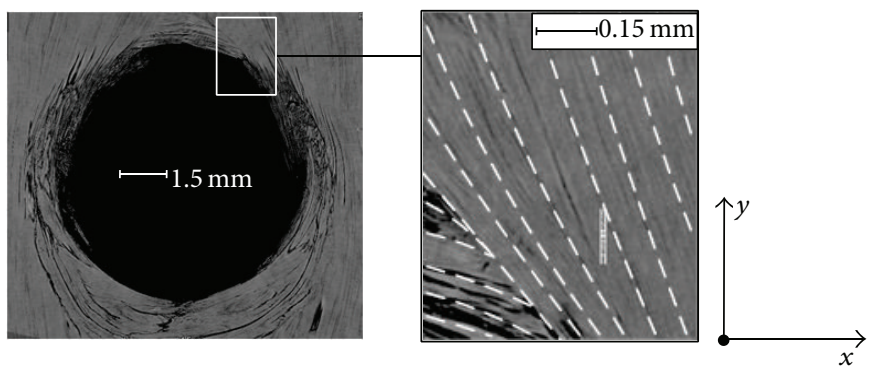

(b)

FIGURE 18: CT scan (voxel-resolution $4.8 \mu \mathrm{m}$ ) of hybrid joints: (a) three-dimensional view of GFRP with marked fiber orientations and (b) top view and detail view of CFRP edge with labeled fiber orientation.

the interrupted force flux, critical failure stresses are induced at the load introduction, which reduce the load capability of the joining system essentially. This can exploit only insufficiently the high lightweight potential of FRP components in highly loaded multimaterial systems. In addition, the often multistage, manual steps such as predrilling of the joining parts and subsequent insertion of extra joining elements represent time-consuming and costly preliminary work in the joining process and require therewith additional material and energy expenditure.

The present work describes the development of an automated and load path adjusted joining technique for mass production of multimaterial design assemblies with thinwalled thermoplastic composites and metal components. For the first time, thermoforming processes, such as the flow drilling of sleeves at metals and warm forming of bore holes at thermoplastic composites, were combined in one process and implemented in a new technology concept.

In the new method, a bushing is formed out of the metallic material by a rotating mandrel, wherein the metallic component is locally plasticized. At the same time-caused by local heating-the polymer matrix material of the FRP component becomes locally plasticized. When forming the sleeve through the FRP, fibers are moved along the load paths-analogous to designs in nature such as knotholes trees. Finally, by defined everting of the sleeve, the joining partners are joined positively and nonpositively so that no extra joining element is needed, which evokes further advantages in weight and costs. In addition, the new joining system is characterized by short process times and the high degree of automation and, in particular, by the high-strength. This new joining technology shows higher bearing loads than conventional joining techniques such as hybrid with blind and semihollow rivets as well as FDS screws.

Based on these findings, a new research project could be initiated, which aims to design, manufacture, and implement a novel lightweight robotic joining tong, so that more complex and thick-walled components can be joined within shorter cycle times (Figure 19).

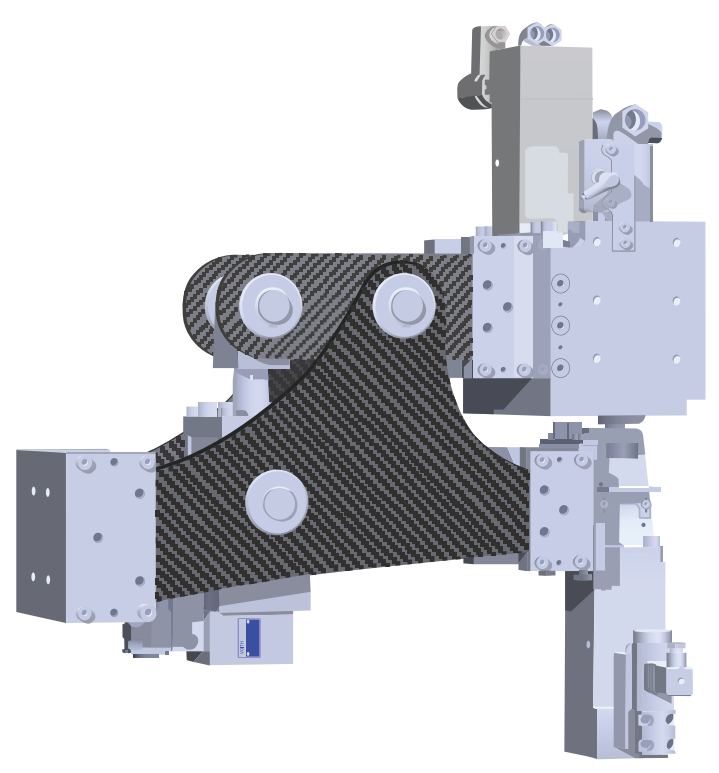

FIGURE 19: Novel lightweight robotic joining tong.

Further experimental studies are used to develop tight joints and combined joining techniques (hybrid joining), to apply the new joining method at lightweight MMD vehicles for the next generation.

\section{Conflict of Interests}

The authors declare that there is no conflict of interests regarding the publication of this paper.

\section{Acknowledgments}

This work was performed within the Federal Cluster of Excellence EXC 1075 "MERGE Technologies for Multifunctional Lightweight Structures" and supported by the German Research Foundation (DFG). Financial support is 
gratefully acknowledged. The publication costs of this paper were funded by the German Research Foundation/DFG (Geschäftszeichen INST 270/219-1) and the Chemnitz University of Technology in the funding programme Open Access Publishing.

\section{References}

[1] T. K. Hwee, Fibre - Reinforced Polymer Reinforcement for Concrete Structures (2), World Scientific Publishing, Singapore, 2003.

[2] D. V. Rosato, Reinforced Plastics Handbook, Elsevier, 2005.

[3] L. Ulke-Winter, M. Klaerner, and L. Kroll, "Determining the damping behavior of fiber reinforced composites: a new approach to find mathematical relationships in data sets," Composite Structures, vol. 100, pp. 34-39, 2013.

[4] T. Davison, "Advanced technology of automotive front-end," Automotive Industries AI, vol. 191, no. 9, 2011.

[5] H. Börger, H. Schwarz, and P. Myard, "New hybrid structures all in PA6: why?” JEC Composites Magazine, no. 14, pp. 52-53, 2005.

[6] H. Seidlitz, L. Kroll, M. Bilgin, J. Kaufmann, and M. Heinrich, DE 102009012578A1: Energieabsorptionselement für einen Kraftwagen, Daimler AG, 2009.

[7] M. M. Schwartz, Joining of Composite-Matrix Materials, ASM International, 1995.

[8] D. D. L. Chung, Composite Materials: Science and Applications, vol. 2 of Engineering Materials and Processes, Springer, 2010.

[9] S. L. Gunderson and J. A. Lute, "The use of preformed holes for increased strength and damage tolerance of advanced composites," Journal of Reinforced Plastics and Composites, vol. 12, no. 5, pp. 559-569, 1993.

[10] H. J. Lin and S. H. Yang, "Modeling and analysis of composite laminates with continuous fiber around in circular hole," Journal of Composite Materials, vol. 27, no. 5, pp. 513-525, 1993.

[11] C. Mattheck, Trees-The Mechanical Design, Springer, New York, NY, USA, 1996.

[12] L. Kroll, "Textilverstärkte Kunststoffbauteile in funktionsintegrierender Leichtbauweise," in Medizintechnik-Life Science Engineering, vol. 5, pp. 343-356, Springer, 2009.

[13] H. Temmen, R. Degenhardt, and T. Raible, "Tailored fibre placement optimization tool," in Proceedings of the 25th Congress of the International Council of the Aeronautical Sciences (ICAS '06), vol. 4, pp. 2462-2471, 2006.

[14] C. A. Brebbia, Design and Nature III Comparing Design in Nature with Science and Engineering, vol. 87, WIT Press, 2006.

[15] H. Ghiasi, K. Fayazbakhsh, D. Pasini, and L. Lessard, "Optimum stacking sequence design of composite materials. Part II. Variable stiffness design," Composite Structures, vol. 93, no. 1, pp. 113, 2010.

[16] D. Reuschel and C. Mattheck, "Optimization of fiber arrangement with CAIO (computer aided internal optimization) and application to tensile samples," in Proceedings of the International Conference on Computer Aided Optimum Design of Structures (OPTI '99), vol. 5, pp. 247-255, 1999. 

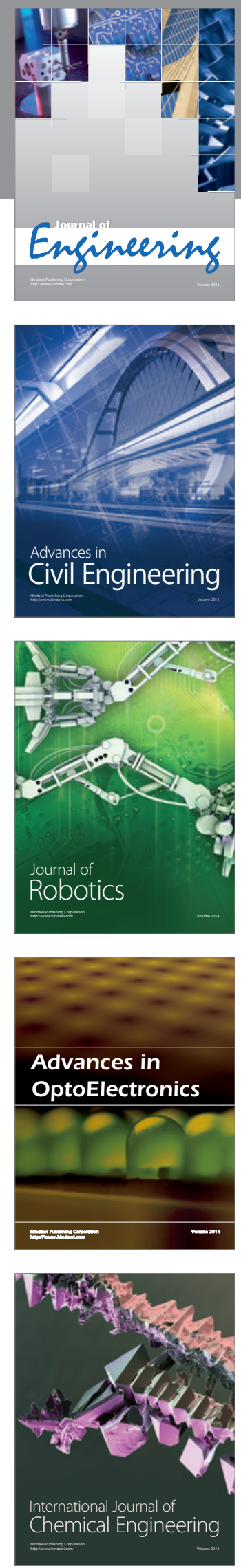

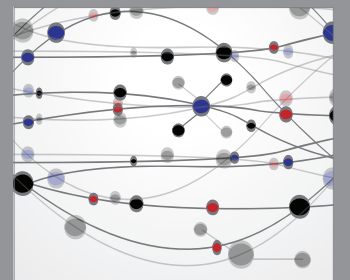

The Scientific World Journal
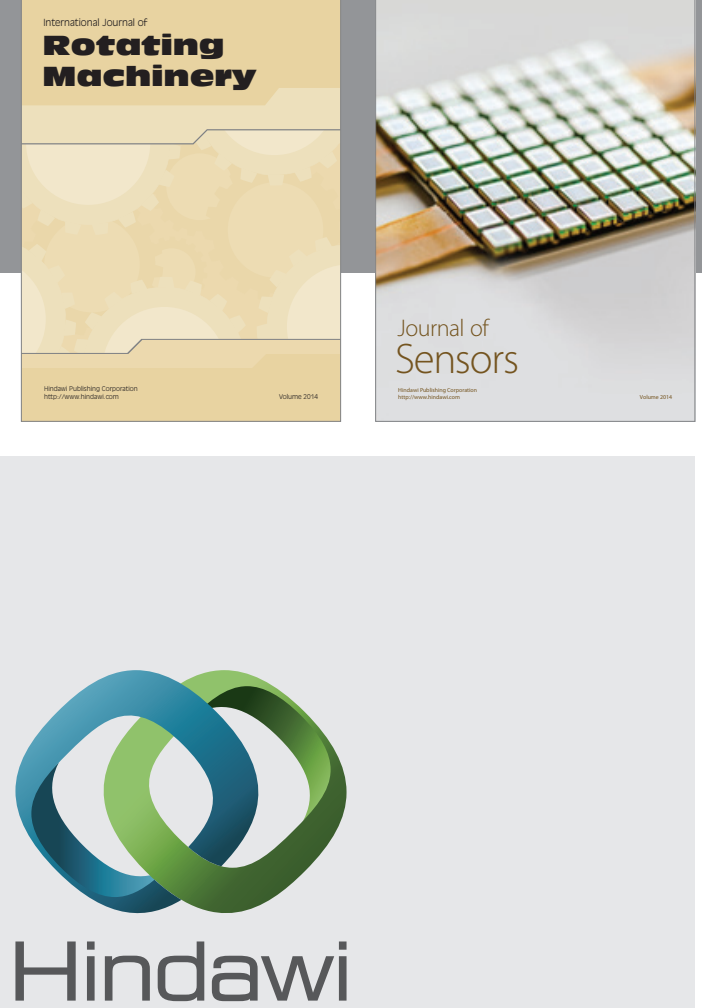

Submit your manuscripts at http://www.hindawi.com
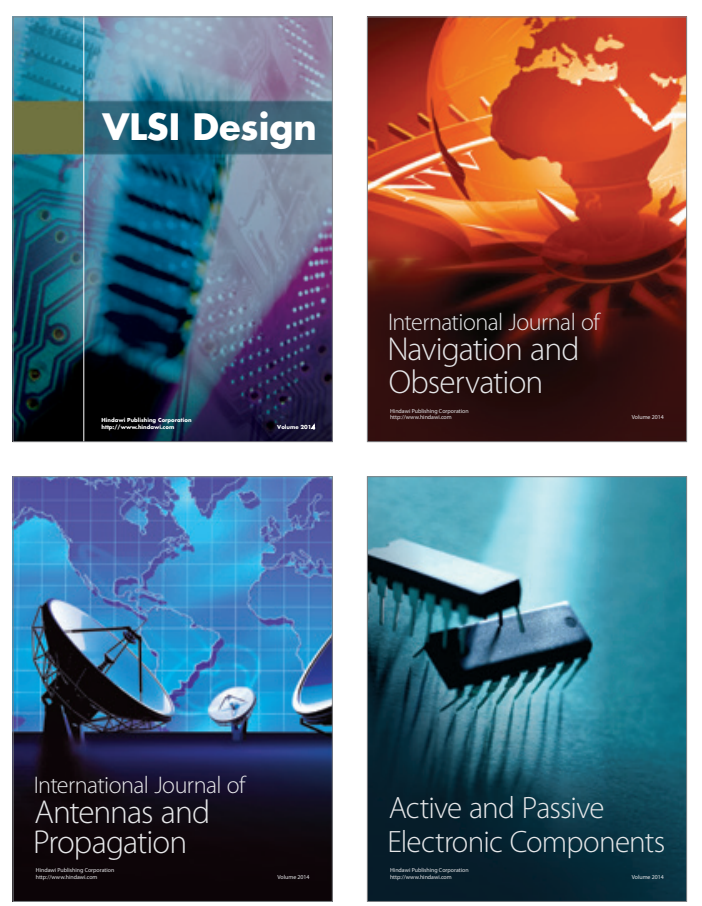
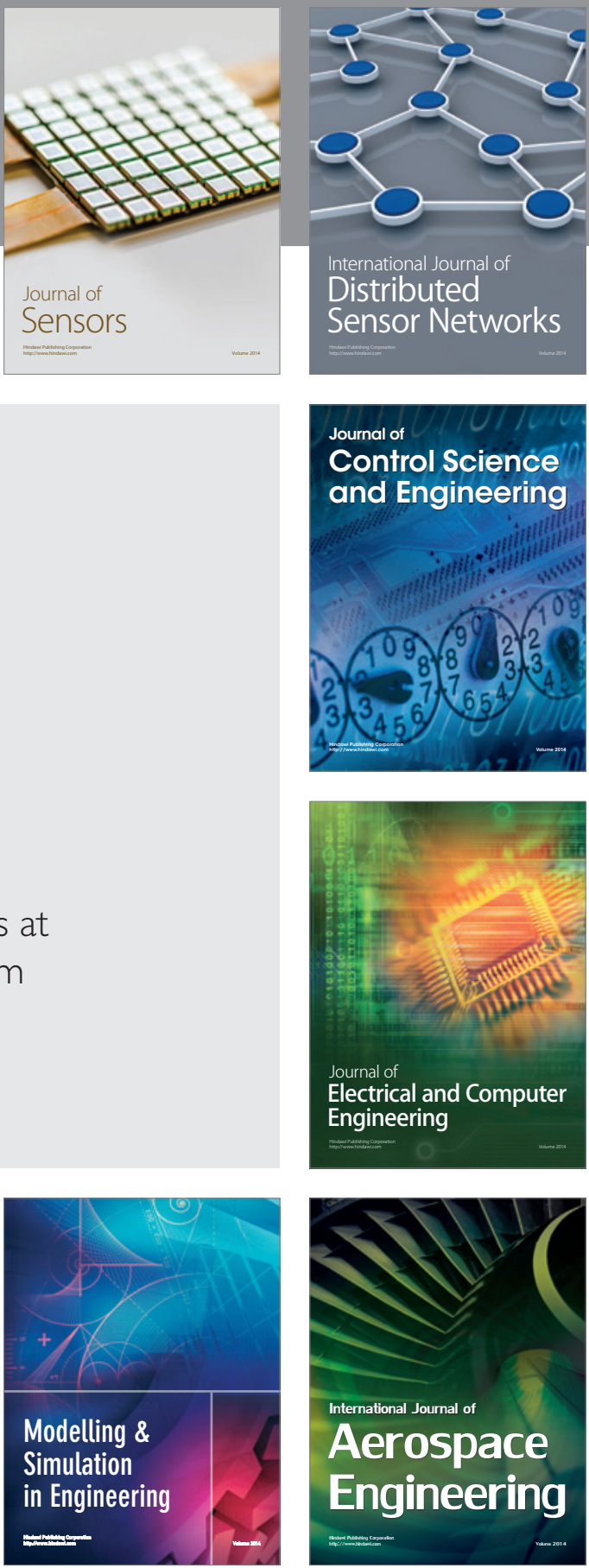

Journal of

Control Science

and Engineering
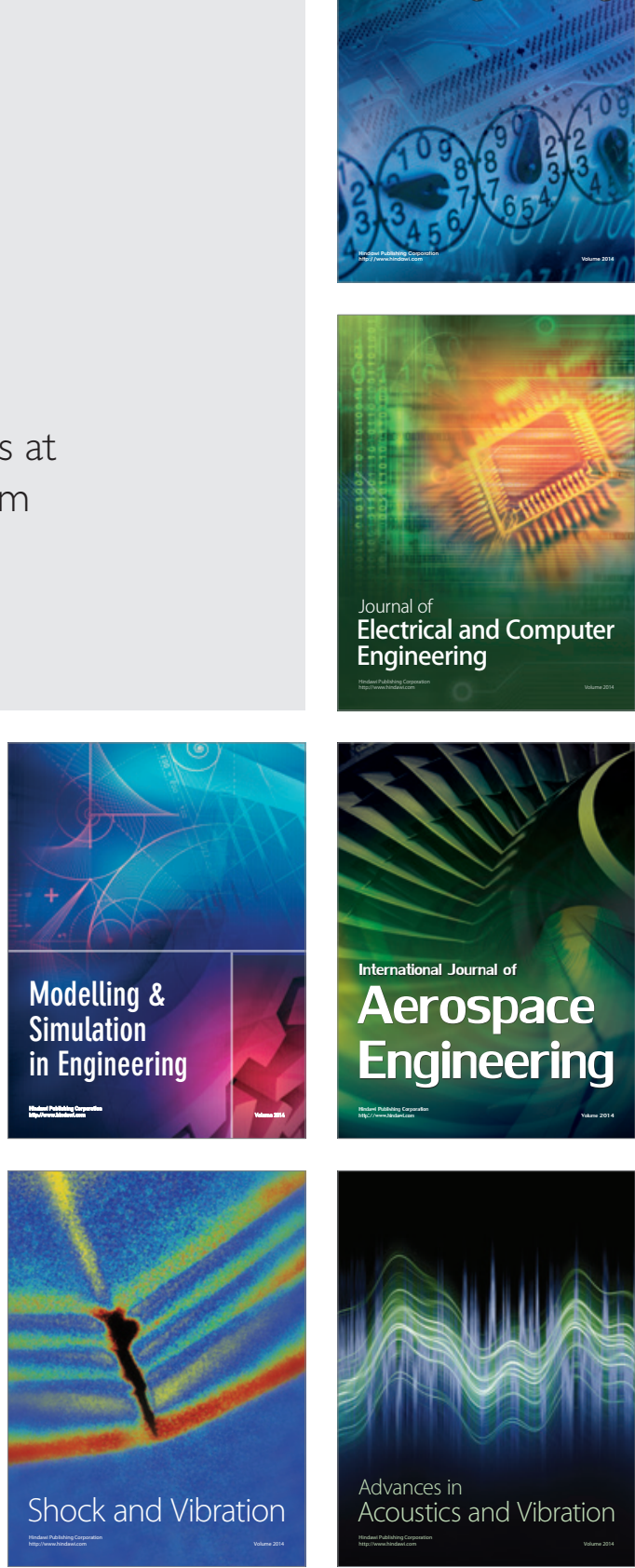